\section{Philosophy and Practice of Medical Ethics}

British Medical Association, 139 pages, London, £9.95, British Medical Association, 1988

In 1980 the BMA produced The Handbook of Medical Ethics in an attempt, according to its foreword, to 'set down in co-ordinated form the [medical] profession's approach to its ethical responsibilities'. After minor modifications and several reprints, it now appears in new guise; longer by a third, substantially revised, and retitled Philosophy and Practice of Medical Ethics.

The change of title indicates that more space is given over to the philosophical arguments underpinning practical ethics, but a book of this nature and length cannot hope to condense the large and growing literature on philosophical medical ethics into a brief introductory chapter without distortion and ommissions. The authors acknowledge the necessary superficiality in their account of the religious and philosophical influences upon medical ethics, and although at times the text smacks of writing by committee, they manage to give proper acknowledgement to the central place of Christian theology in the development of Western medical ethics, and provide a useful, if brief, survey of the relevant contributions from Judaism, Islam, Buddhism and Hinduism. The philosophical influences receive a more cavalier treatment, disposed of as a list of 'principles' (among them utilitarianism, sanctity of life, autonomy, and truth-telling) with no indication of where they come from, how they are related, and what happens when they conflict. The chapter ends with a quote to the effect that 'One cannot afford the uncertainties of the philosopher'.

There follows what may be the core of the book: three chapters on autonomy and paternalism, confidentiality, and consent to treatment, covering the central features common to nearly all doctor-patient relationships. Legal aspects are touched on where relevant, and there is an instructive review of the Lords' judgement in the Gillick case. Such matters concern all doctors: the next few chapters are focussed on the ethical questions arising for particular sub-groups of doctors, such as prison doctors, police surgeons and community physicians. There is a section on torture, reiterating the conclusions of the BMA's 1986 Torture Report: but, disappointingly, no reference to the probity of medical participation in capital punishment.

Then, after five chapters on an area best described as medical etiquette or, as here, professional behaviour, encompassing such matters as gifts and hospitality and establishing a practice, there appears an entirely new section on resource allocation and the reduction of services to patients. Its inclusion is eloquent testimony to the sense of threat now pervading the NHS at all levels, and is likely to raise some government hackles.

Continuing ethical dilemmas are covered in two sections, one for those issues where a consensus is identified (including, contentiously, abortion) and one for those where it is not (including, equally contentiously, given the clarity of the conclusions of the BMA's 1988 report on the subject, euthanasia). Finally there is a valuable collection of 15 different codes of practice and declarations of the World Medical Association, a set of appendices giving guidelines on specific matters like the use of fetal tissue in transplants, a concise bibliography, classified by subject, and an index.

Apart from an idiosyncratic distinction between ethics and morals, some lapses of expression, and occasional typographical errors (one of which, by referring to a 1976 report's opinion that brain death 'could be diagnosed with uncertainty', will be seized upon by the small but strident anti-brain death lobby) the book will be a useful practical guide to doctors facing dilemmas, and perhaps a stimulus to further thought on deeper issues in medical ethics.

DR S G POTTS,

Registrar, Maudsley Hospital, London

\section{No Fault Compensation in Medicine}

Edited by Ronald D Mann and John Harvard, xv $+210+$ appendices, London, $£ 20.00$, Royal Society of Medicine Services Ltd, 1989

The issue of no-fault compensation for the victims of medical accidents is now firmly on the medico-political agenda, at least so far as the British Medical Association and the defence societies are concerned. Although the BMA has had a working party on the subject since 1983, the general perception is that their proposals are largely a response to the expansion in the numbers of claims for compensation made against doctors in the $1980 \mathrm{~s}$, with the concomitant increase in subscriptions to the defence societies. This view is supported by the fact that in evidence presented to the Pearson Commission in the 1970 s the medical profession was opposed to a nofault scheme, principally because it would tend to reduce accountability. Now that Crown indemnity has been introduced (from January 1990), providing for compensation for medical negligence within NHS hospitals to be met fully from NHS funds, it will be interesting to see how strong the BMA's 
commitment to no-fault remains.

This question of the motivation underlying the pressure for a no-fault scheme might appear to be somewhat peripheral to the issue of whether such a scheme should be introduced, but in truth it is crucial. It is obvious that the terms and scope of any scheme (and hence, most fundamentally, its cost) must depend on its purpose. If the purpose is to compensate the victims of 'medical accidents' regardless of proving that someone was at fault the scheme will cast a wide net and be expensive to run. If the purpose is to reduce the level of medical malpractice litigation the scheme will adopt narrow eligibility criteria (in the definition of what constitutes a 'medical accident') which, in the words of the Pearson Commission, might do little more than convert the ordinary test of negligence in tort into a statutory formula. Moreover, by casting the question of medical negligence in terms of compensation for the injured patient, a no-fault scheme simply overlooks other equally important aspects of medical malpractice: accountability of the medical profession to patients; the setting and maintenance of standards within the profession; the attitudes of doctors to patients who have suffered medical injury.

No Fault Compensation in Medicine is a record of the proceedings of a joint meeting of the Royal Society of Medicine and the British Medical Association held in January 1989. The collected papers provide an excellent account of the arguments both for and against the introduction of such a scheme into the UK, including detailed information on the operation of existing schemes in Sweden, New Zealand and Finland. What is patently clear is that no-fault is not a panacea for all of the perceived ills of malpractice litigation. The tort system is undoubtedly flawed: it is expensive, slow, arbitrary in its effect (depending, as it does, upon proof of negligence and causation), available only to the poorest (who qualify for Legal Aid) or the richest of patients, stressful to litigants, and can result in the breakdown of doctor/ patient relationships (the 'wall of silence'). A no-fault scheme would provide easier access to compensation and reduce delay, but the criteria for eligibility are themselves arbitrary (see pp 94-95), levels of compensation would have to be lower to keep overall costs down (p 95), it removes any element of accountability through the courts without suggesting how this should be replaced (p 72), and it would not necessarily contribute to an improvement in doctor/patient relationships (though of p 69).

Perhaps more fundamental is the question why the victims of medical accidents (and only some of these, bearing in mind the eligibility criteria) should be in a privileged position in terms of claiming compensation compared to other accident victims (say at work or on the road) when the compensation is to be paid by the state ie by all taxpayers. The philosophical justification for no-fault schemes is that compensation for injury or disability should not depend on the entirely arbitrary criterion of causation, and the logic of this is that schemes should be fully comprehensive, even to the extent of refusing to distinguish between injury by accident, congenital disability or disease (a point that is now recognised in New Zealand). Distinguishing between different types of accidental injury is even more illogical. Nowhere in No Fault Compensation in Medicine is the argument presented as to why medical accidents should be in a special category (though this is not to suggest that a pragmatic case could not be made).

A useful question to ask in assessing the merits of a proposal to introduce nofault compensation for the victims of medical accidents is whose interests would such a scheme serve? In this regard it is worth bearing in mind that it is the doctors' trade union, the BMA, which is in favour of the proposal and Action for the Victims of Medical Accidents (AVMA), the only organisation which represents the interests of injured patients, which is opposed. This may seem odd to someone unfamiliar with the background, but it simply exposes the hidden agendas. The fundamental concern of doctors should not be with the mechanism by which injured patients receive financial recompense, but with caring for the patient (which involves explaining what went wrong), improving standards and seeking to avoid similar accidents in the future. This process necessarily involves identifying and correcting errors, and where appropriate allocating responsibility. This cannot be achieved under the banner of 'no-fault', which to some implies that culpable errors are irrelevant. For doctors, medical negligence should be first and foremost an ethical, rather than a medico-legal, issue. After all, it is difficult to abide by the principle of non-maleficence by refusing to acknowledge and respond to the problems of 'fault'.
MICHAEL A JONES, Senior Lecturer in Law, University of Liverpool

\section{Medicine and the Law}

Paul Knapman and Iain West, 185 pages, Oxford, £8.95, Heinemann Medical, 1989

This is one of Heinemann Medical's 'Student Reviews', intended to supplement the lecture courses in various subjects.

A small paperback, it is remarkable for the amount of useful information packed within its 185 pages. Written by a London coroner and a forensic pathologist at Guy's Hospital, this dual authorship is reflected in the two main divisions of the book. The first half deals with the legal aspects of medicine and the remainder with forensic medicine and toxicology. Useful appendices offer factual information on medical certification, reporting deaths to coroners and industrial deaths. The legal section spans the usual matters such as medical negligence, the GMC ethics, the courts, consent, confidentiality and similar topics. Some of this shows a certain legal idiosyncrasy here and there and because the book is small, the inevitable condensation of difficult subjects, such as brain death, leaves some ambiguity. Perhaps a more systematic treatment of the legal principles of malpractice could have been given in place of some of the leading case reports, which take too much space in a book of this size. The sections on death certification and the practicalities of doctor-coroner relationships are excellent, as might be expected from a coroner author. A few factual errors of little importance tend to have crept in, such as the membership of the GMC which is now 102, not 95 as stated. There is a very useful chapter on complaints in the NHS, which is not usually found in this type of book.

The other half of the text is at least of equal value, covering in a very practical way the mainstream topics usually found in forensic manuals. Again space has been a difficult constraint, but Iain West has made the best possible use of his hundred pages. The use of tabulated information has compressed much material into a compact form. Once again, the range and treatment is conventional, which is what the over- 